\title{
Study on the Transmission Principle of Spur Gear with the Constant Instantaneous Contact Ratio
}

\author{
Xia Han \\ Engineering College, Heilongjiang Bayi Agricultural \\ University \\ Da Qing, China \\ hxneu@126.com \\ Tianxiang Liu \\ Engineering College, Heilongjiang Bayi Agricultural \\ University \\ Da Qing, China \\ Xiang302@sina.com
}

\author{
Shu Jun Li \\ School of Mechanical Engineering and Automation, \\ Northeastern University \\ Shen Yang, China \\ sjli_cn@yahoo.com.cn \\ Jijun Zhang \\ Engineering College, Heilongjiang Bayi Agricultural \\ University \\ Da Qing, China \\ Zhang_ji_jun2009@163.com
}

\begin{abstract}
In the gear transmission system, especially, during the gear meshing transmission process of high-speed, heavy duty gear system, during a very short time of mono-, bis-teeth alternately meshing, the tooth mutation is generated by the loads, the tooth exciting and changes of tooth meshing stiffness are generated, resulting in the generation of vibration and noise. In order to investigate and solve the problems of vibration and noise, this paper start to consider from instantaneous contact ratio angle, introduces a way to improve the spur gear transmission stability.
\end{abstract}

Keywords-Instantaneous contact ratio; Gear transmission; Stability

\section{INTRODUCTION}

The gear transmission is one of the most important and the most widely used forms in the transmission machinery. In certain extent, technology level of the gears production, affect the development level of the machinery industry of the State. With the rapid development of modern science and technology and industry, mechanical products are developed to the directions of the large-scale and high-performance, the transmission requirements of high-power, high-speed, heavyduty, high stability and low noise are the important features and development trends. Due to inevitable the presence of the manufacturing and mounting errors for gear tooth, the elastic deformation of the tooth loaded, bending and torsional deformation and heat distortion of the gear shaft, These factors make the gear to generate impact, vibration and noise in the meshing transmission, to reduce the running stability. Especially for high-speed, heavy-duty gear, it will seriously affect the transmission quality. In order to improve the meshing performance of gear teeth, method of tooth modification commonly is used as the main resolve way internationally. Due to the complex structure of specialized equipment, high cost, therefore, the manufacturing cost is high for the repair shaped gear, limiting its wide application.
In recent years, many studies at home and abroad were developed to improve the transmission performance of the gear[1-5], manufacturing technology for the gear also corresponding developed quickly. Especially on the teeth grinding of hardened gear, In the Europe and the United States, some of the advanced gear manufacturers were committed to the research of special trimming technology, and remarkable results have been achieved, However, the technology about this aspect is strictly confidential as intellectual property, therefore, the references about this aspect are less, Some domestic research institutes and enterprises also committed to the gear modification research and the exploration of ways improving engagement quality[6-8], because of a relatively small investment, and lack of innovative solutions, the gaps of overall level are larger than foreign advanced level. Therefore, how to reduce the impact, the vibration, and noise generated during the gear transmission, improve the running stability, it has been one of the hot research topics for the domestic and foreign scholars in the field of mechanical transmission.

\section{THE REASONS ANALYSIS AFFECTING THE TRANSMISSION QUALITY OF GEAR}

Many research results show that, due to the presence of the elastic deformation loaded, thermal deformation, manufacturing error during gear pairs operation, interference phenomena will be produced at the alternately meshing point between the single tooth pair and double tooth pair, to cause the impact of gear pairs in biting in and gnawing out, the alternately meshing between the single tooth pair and double tooth pair, resulting in the teeth by the uneven loading and unequal elastic deformation, meshing stiffness of the tooth changes periodically, these are one of the main reasons generated impact, vibration and noise. Further, in a very short time the alternately meshing between the single tooth pair and double tooth pair, the tooth mutation is generated by the loads, the tooth exciting is the other main reason produced vibration 
and noise for the high-speed and heavy gear[3, 5, 811].Summarizing the existing research, it shows that, the changes of meshing stiffness(As shown in figure 1) by the alternately meshing (contact ratio is not continuous) between the single tooth pair and double tooth pair during the gear transmission process, is the primary one of the direct causes generated vibration and noise, this is the inevitable "original defects" ,because of the design of the structure or parameters of the gear, therefore, regarded as "inevitable" and trying the modification method to remedy. To resolve the impact, vibration and noise problems during the gear transmission, if the research can start directly from the discontinuous contact ratio, the reason of contact ratio change will be eliminated from the origin of gear transmission process, so that the gear pairs involved in the meshing gear keep constant in each instantaneous, contact ratio reach to instantaneous constant. A new meshing transmission principle can be introduced to solve this problem, it appears to be very reasonable to explore a new way to improve the meshing quality and drive performance of the gears.

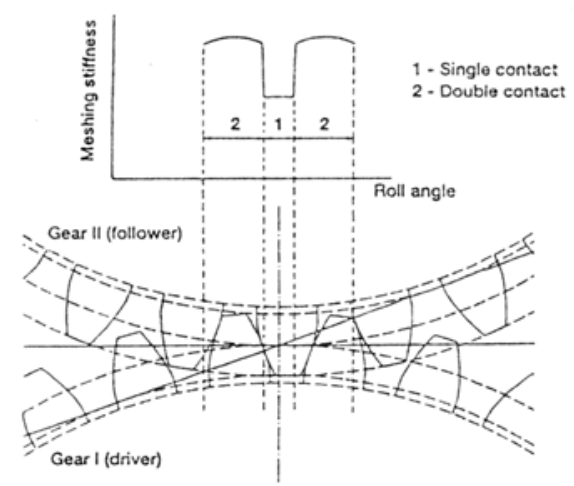

Fig. 1 The meshing stiffness when the contact ratio is $1.668[3]$

\section{THE PROPOSING OF SPUR GEAR TRANSMISSION PRINCIPLE WHEN THE INSTANTANEOUS CONTACT RATIO IS A CONSTANT}

As is known, gear contact ratio $\varepsilon$ is the average number of meshing teeth pairs at the same time participant during the gears meshing transmission process, for example, $\varepsilon=1.668$,shows that in average of 1.668 pairs of teeth participate in meshing, $0.668 \mathrm{P}_{\mathrm{b}}$ is the actual meshing line both sides, as double-teeth meshing region, $0.332 \mathrm{P}_{\mathrm{b}}$ is in the middle, as single-teeth meshing region, therefore it can be said that instantaneous contact ratio is uncontinuous and alternating changes, as shown in figure 1 .

To achieve instantaneous contact ratio be constant gear transmission, gear meshing zone of complete equal pairs teeth should be formed in the actual meshing line. To achieve this goal, for the spur gear transmission, require transverse contact ratio of mutual meshing gear to be integer (for example $\varepsilon=1,2, \cdots)$, Or, it should be able to be done, that involved in meshing the teeth of gears at the same time can be arranged according to certain rules in the actual meshing zone, to make single-double teeth be alternate complementary in the meshing zone. Conventional gear, due to the structural constraints or the gear parameters design, it often can not meet the requirements.

To achieve instantaneous contact ratio be constant gear transmission, it can be done that the gear meshing timing can be adjusted and distributed, to make single-double teeth be alternate complementary in the meshing zone, gear meshing zone of complete equal pairs teeth should be formed in the actual meshing line. Based on the viewpoints of adjusting and distributing the meshing timing, the structure of meshing drive gear should include the characteristics with a plurality of pairs of teeth involved in meshing at the same time. Therefore, if the traditional spur gear is discreted, that is, the spur gears are discreted to form stepped gear with two or more columns according to certain rules derangement, when meshing transmission, it can be done that meshing timing of all columns of the gears can be adjusted and distributed, to make singledouble teeth be alternate complementary in the meshing zone, gear meshing zone of complete equal pairs teeth should be formed in the actual meshing line. thus, at any point of the actual meshing line, the teeth pairs of involving in meshing can be constant, that is, instantaneous contact ratio be constant. Take the most intuitive straight gear transmission of $\varepsilon=1.5$ as an example, the gears of instantaneous constant contact ratio are composed by at least two columb of gears tooth, central angle $\varphi$ is shown in figure 2, corresponding with the phase difference of $0.5 \mathrm{p}_{\mathrm{b}}$, the status of two columb gears meshing at the same time is formed, in each instantaneous time ,there are three pairs of tooth to be participated in meshing.

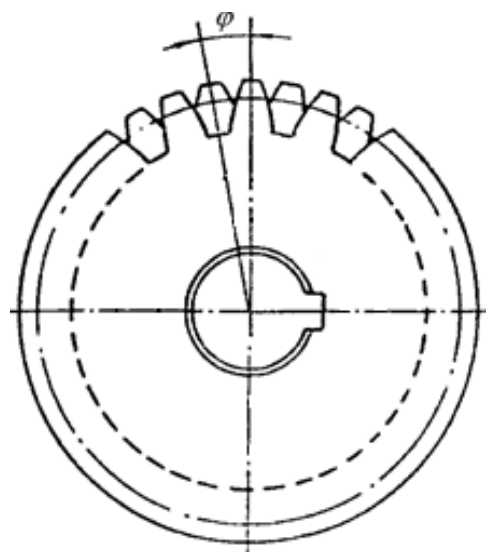

Fig. 2 The phase angle of stepped gear when its one-layer's $\varepsilon$ is equal to 1.5

If it can be done ,that meshing transmission of gears can reach to instantaneous constant contact ratio through the spur gears are discreted to form stepped gears, then, straight gear transmission will be equivalent to the helical gears transmission, progressive meshing effect will be generated, to improve the transmission stationarity. And, axial force will not be generated during the transmission of stepped gears, traditional methods used to manufacture various types of spur gears can be also used in manufacturing stepped gear, compared with helical gear manufacturing, it will greatly simplify the manufacturing process and reduce costs, practical value is existing. Therefore, 
the introduction of transmission principle of instantaneous constant contact ratio gears, to explore a new way to improve the gears meshing quality and transmission performance.

Straight gear transmission designed by any non-integer contact ratio gears, when gear transmission conditions meet the instantaneous constant contact ratio, how to configure corresponding stepped gears? For gears transmission of different types of tooth profile, in addition to the stepped tooth, which gears structure are there to meet the transmission conditions of instantaneous constant contact ratio? What are the tooth profile shapes? At the same time, how to establish the relationship between the geometric parameters and kinematic parameters in the gear transmission of the instantaneous constant contact ratio, to solve kinematic parameters design, to solve structure styles of different types gears transmission, manufacturing method and process. How to create dynamics model of gears transmission of the instantaneous constant contact ratio, meshing stiffness and transmission stability of gears transmission are analyzed, compared and evaluated, provide a theoretical basis in solving the gear shock, vibration and noise problems by the principle. In addition, the errors of addendum and center distance will change contact ratio gears transmission, how to analyze and assess the effect of the errors of addendum and center distance on the transmission performance, to explore solutions to compensate the error influence, to analyze the issues involved adaptability of stepped gears to changes of axial stiffness, progressive meshing performance discreted gears and average loads on the gear tooth, these new issues are will be resolved based on the new principle during the gear meshing transmission.

\section{CONCLUSION}

This study proposes the gear transmission principle of instantaneous constant contact ratio, by solving meshing alternating chance of single-double teeth pairs, suffered loads of each tooth is constant in the process of meshing transmission, meshing stiffness fluctuation of the gears tooth is smaller, undoubtedly, the gears transmission stationarity will be greatly enhanced, this is a new concept to solve the issues, such as a shock, vibration and noise during the highspeed heavy gear transmission. Although the structure of the stepped gear is mentioned in some literatures, but they are two completely different concept and purpose with the study. The gear transmission meshing principle based on instantaneous constant contact ratio, no related research is reported at home and abroad, the study of this problem is not only to explore new theoretical problem for the gear transmission, and based on the study, the related issues can be expanded, have important theoretical significance and academic value. Applying to the principle and combining existing research results, new technology of high-performance gear transmission is expected to develop with independent intellectual property rights, to improve the international competitiveness of gears manufacturing technology and equipment manufacturing industry in our country, undoubtedly, this is a research topic of both academic value, but also important practical significance and application prospects.

\section{REFERENCES}

[1] A. Kahraman, G. W. Blankenship, "Effect of involute tiprelief on dynamic response of spur gear pairs," Transactions of the ASME, J of Mech. Design, vol. 121, pp. 313-315, April 1999.

[2] S. Baud, P. Velex, "Static and dynamic tooth loading in spur and helical gear systems -experiments and model validation," Transactions of the ASME, J of Mech. Design, vol. 124, pp. 334-346, 2002.

[3] Chuen-Huei Liou, Hsiang His Lin, F. B. Oswald, et al, "Effect of contact ratio on spur gear dynamic load with no tooth profile modifications," Transactions of the ASME, Jof Mech. Design, vol. 118, pp. 439-443, 1996.

[4] F. L. Litvin, I. H. Seol, D. Kim, J. Lu, et al, "Kinematic and geometric models of gear drives,"Transactions of the ASME, J of Mech. Design, vol. 118, pp. 544-550, 1996.

[5] Yang Zuoyu. The Transmission Design of Spur Gear with Adjustable Center Distance [J]. Journal of Mechanical Transmission, 1999 (1), pp $39-41$.

[6] Li Shaobin,Li Runfang,Lin Tengjiao.The Cylindrical Gear Teeth Ideal Modification Curve Based On The Coupled Thermo-Elastic Contact Finite Element Method [J]. Chinese Mechanical Engineering, 2003,14(14):1175-1179.

[7] Yanbin, ZHENG Peng, ZHOU Guoxiang, ZHOU Shige. Ausform finishing process for hardened gears and study on gear tooth deformation theory[J]. Journal of Shenyang University of Technology, 2003 (2), pp 4-6.

[8] Xiao Limin,Tang Jinyuan.A New Design Method for Low Noise Gear (One)[J].Manufacturing Technology \& Machine Tool, 1995 (5), pp 3033.

[9] Xiao Limin,Tang Jinyuan.A New Design Method for Low Noise Gear (Two)[J].Manufacturing Technology \& Machine Tool, 1995 (6), pp 3032.

[10] Xiao Limin,Tang Jinyuan.A New Design Method for Low Noise Gear (Three)[J].Manufacturing Technology \& Machine Tool, 1995 (7), pp 27-30.

[11] $\mathrm{Wu}$ Baolin,YANG Sujun,YAO Junhong.Theoretical Analysis on Meshing Impact of Involute Gears[J].Mechanical Science and Technology,2003 (1), pp 54-60. 